\title{
High-intensity focused ultrasound in the treatment of breast tumours
}

\author{
Mirjam C L Peek ${ }^{1}$ and Feng $\mathbf{W u}^{2}$ \\ ${ }^{1}$ Research Oncology, Division of Cancer Studies, King's College London, Guy's Hospital Campus, Great Maze Pond, London SE1 9RT, UK \\ ${ }^{2}$ HIFU Unit, The Churchill Hospital, Oxford University Hospitals, Headington, Oxford OX3 7LJ, UK
}

Correspondence to: Mirjam CL Peek. Email: mirjam.peek@gstt.nhs.uk

\begin{abstract}
High-intensity focused ultrasound (HIFU) is a minimally invasive technique that has been used for the treatment of both benign and malignant tumours. With HIFU, an ultrasound (US) beam propagates through soft tissue as a high-frequency pressure wave. The US beam is focused at a small target volume, and due to the energy building up at this site, the temperature rises, causing coagulative necrosis and protein denaturation within a few seconds. HIFU is capable of providing a completely non-invasive treatment without causing damage to the directly adjacent tissues. HIFU can be either guided by US or magnetic resonance imaging (MRI). Guided imaging is used to plan the treatment, detect any movement during the treatment and monitor response in real-time. This review describes the history of HIFU, the HIFU technique, available devices and gives an overview of the published literature in the treatment of benign and malignant breast tumours with HIFU.
\end{abstract}

Keywords: high-intensity focused ultrasound (HIFU), breast cancer

Published: 10/01/2018

Received: 27/03/2017

ecancer 2018, 12:794 https://doi.org/10.3332/ecancer.2018.794

Copyright: $\odot$ the authors; licensee ecancermedicalscience. This is an Open Access article distributed under the terms of the Creative Commons Attribution License (http://creativecommons.org/licenses/by/3.0), which permits unrestricted use, distribution, and reproduction in any medium, provided the original work is properly cited. 


\section{Background}

Breast cancer is the most common cancer in women in the United Kingdom with a one in eight lifetime risk. In 2014, just over 55,000 women were diagnosed and over 11,400 women died from breast cancer, making it the second most common cause of death from cancer in women [1]. Mammographic screening programmes and improved imaging technologies have led to the detection and diagnosis of breast cancer at an earlier stage [2, 3]. However, it has also increased the number of detected benign lesions such as fibroadenomata (FAD). FAD is the most common benign breast lesion in women and the standard of care is reassurance [4]. Active treatment is reserved for symptomatic patients [4]. The standard of care for breast cancer is surgery in the form of either breast conservation or mastectomy followed by adjuvant therapy [5]. However, an increasing number of patients are not satisfied with their cosmetic result after breast surgery. Lesser invasive treatments like radiofrequency ablation, cryo-ablation and laser ablation have become more popular over the years; these techniques show promising results with an improved cosmetic outcome and a decrease in morbidity. Furthermore, for patients with many co-morbidities, lesser invasive treatments offer the opportunity to treat without a life-threatening procedure $[3,6]$.

High-intensity focused ultrasound (HIFU) is a non-invasive technique that has been used for the treatment of both benign and malignant tumours. With HIFU, an ultrasound (US) beam propagates through soft tissue as a pressure wave with a high frequency. The US beam is focused at a small target volume resulting in a conversion of energy into heat at this site. This increase in temperature causes coagulative necrosis and protein denaturation within only a few seconds [7, 8]. HIFU is capable of providing a completely non-invasive treatment without causing damage to the direct adjacent tissues [7]. This review explains the history of HIFU, the HIFU technique, available devices and gives an overview of the literature published up to December 2016, about HIFU in the treatment of breast tumours.

\section{History of HIFU}

The first therapeutic use of focused US (FUS) was by Bradley et al [9], who designed a specially adapted frame and US transducer and successfully used it on patients to treat psychiatric disorders. The study did not continue due to a lack of imaging and the need for craniotomies. In 1962, William Fry and Russell Myers utilised FUS for the treatment of fifty patients with Parkinson's disease and although the symptoms disappeared, FUS was not used thereafter, due to the development of L-dopa [10]. The first successful use of FUS in breast cancer and thyroid cancer was in 1964 by Oka et al [11]. In the 1970s, US was used with lower intensities for the treatment of tumours after the discovery that cancer cells are more sensitive to heat than normal cells $[12,13]$. The aim was to induce hyperthermia in the complete tumour lesion and maintain hyperthermia for approximately an hour. Due to a lack of heating and maintenance in the entire tumour volume, caused by a lack of feedback control of the delivered acoustic power to the tumour, this application of FUS did not manage to set grounds [13]. The first clinical application of HIFU was the use of extracorporeal shockwave lithotripsy as a method for treating kidney stones [13] and due to the development of modern technology and advanced imaging methods, interest in HIFU was revived in the 1990s, realising that it can produce instant cell death to the focused areas of tissue. Currently, HIFU has been used in the treatment of both benign and malignant tumours in the liver, breast kidney, uterine and prostate [14].

\section{The HIFU technique}

In HIFU, a US wave propagates from the transducer through the different tissue layers towards the target site (Figure 1). A part of the energy carried by the sound wave is reflected every time the US wave reaches a tissue boundary, whilst the remaining energy will pass through the tissue layer. The amount of energy that passes through is dependent on the density of the tissue, the speed of sound within tissue layers and the thickness of the tissue layers. It is therefore important to minimize the effect of reflection at the tissue boundaries, as it will otherwise not be feasible to reach the target $[14,15]$. When a US wave moves through a soft tissue layer, shearing motion is generated by the induced pressure fluctuations, which results in frictional heating. When a US wave propagates through inhomogeneous media, the wave is scattered in all directions, due to the small regions with different properties within this media, compared to their surroundings, resulting in a loss in acoustic energy $[14,16]$. The attenuation coefficient is related to the US frequency and is therefore in most tissues ideal for the use of non-invasive treatment. However, problems arise when the US excitation frequency is increased, which causes both the absorption coefficient and the attenuation coefficient to increase, resulting in a higher heat disposition and a lower penetration depth [14, 16]. As a result, the optimal treatment frequency is dependent on the application; a compromise is needed between the desired penetration depth and the hyperthermia rate [14, 16, 17]. 


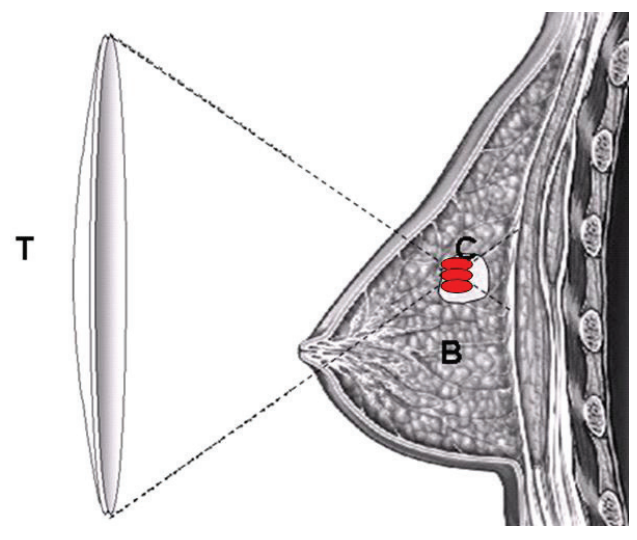

Figure 1. Schematic diagram demonstrating the principle of HIFU ablation for breast tumour. US energy is focused into a small volume in which US energy is converted into heat to induce the required thermal ablation of a targeted breast tumour; (T) - HIFU transducer, (B) - normal breast tissue and $(\mathrm{C})$ - the targeted breast tumour.

When a US wave propagates linearly through soft tissue, the hyperthermia rate is dependent on the incident US intensity and the local tissue absorption coefficient. Any non-linear mechanism that gives rise to higher frequency components in the US wave will produce enhanced heating due to the frequency dependency of the absorption coefficient previously described. Two mechanisms play an important role in HIFU; non-linear wave propagation and cavitation $[14,18]$.

In non-linear wave propagation, the US wave becomes gradually shocked resulting in energy loss from the excitation frequency to higher frequencies. The extent of this loss is dependent on the amplitude of the incident wave, the non-linearity of the medium and the travel distance of the US wave. The non-linear effects become more significant in HIFU when there is an increased treatment depth or when a region of high intensity is similar to a region of fatty tissue, which has a higher amount of non-linearity. In HIFU, the heating observed is contributed to significantly by non-linear wave propagation $[13,14]$.

Small cavities can arise from the thermal effects alone or if the peak rarefaction pressure of a US wave with large amplitude is large enough. When the tissue's boiling point is reached, large vapour bubbles are formed; the behaviour of these cavities is known as acoustic cavitation, and this process can be divided into two types: stable and inertial cavitation. The type of cavitation is dependent on the size of the bubbles compared to the resonance size, the excitation frequency and the contribution of vapour and gas pressure on the total pressure inside the cavitation. Stable cavitation describes the repeated oscillations of cavities with a size close to or greater than the linear resonance size for the excitation frequency; inertial cavitation describes the explosive growth of cavities with an initial size of about one-third of the resonance size followed by the intense collapse under the effect of the inertia of the surrounding fluid [13, 14, 16]. Cavitation plays a significant double role in US-induced hyperthermia; acoustic energy is being trapped within the cavity due to the strong scattering of the incident wave. This results in enhanced heating due to viscous absorption of the trapped excess energy. In inertial cavitation, the violent collapse of the bubbles as a result of the redistribution of energy leads to more absorption than attenuation, which results in enhanced heat disposition in the surroundings of the cavity [14]. In HIFU, both inertial cavitation and non-linear wave propagation play a significant role in the hyperthermia induced.

\section{HIFU devices}

For the application in breast, two types of image guidance are available, either US or magnetic resonance imaging (MRI). Guided imaging is used to plan treatment, detect movement during treatment and monitor response in real-time.

HIFU guided by US offers real-time visualisation of the treated volume; it can therefore detect any movements made by the patient during the treatment. Furthermore, US can aid in guidance of the energy disposition within the treated area; when applying the first pulse a hyper-echoic cross (hyper echoic [white] area in the shape of a cross) will become visible during the application once the right energy 
level has been delivered $[8,19]$. Furthermore, after application of the pulse a hyper-echoic mark should be visible once the correct energy level is reached. This mark is a representation of the level of coagulative necrosis in real-time during treatment [14]. Other potential benefits of US-guided HIFU are lower cost, increased mobility of the device and wider availability of US [20]. Currently, there are two USguided devices on the market. The Echopulse device (Theraclion, Malakoff, France) has received a specific CE-mark for the treatment of breast and thyroid nodules. The device includes a cooling and coupling component to cool the skin, in order to prevent any heat-related side effects of the skin such as hyperpigmentation or a skin burn. Cooling does not affect the efficacy of the treatment and can be used for all applications with tumours relatively close to the skin. The device uses a $7.5-12 \mathrm{MHz}$ diagnostic transducer and a $3.0 \mathrm{MHz}$ therapeutic imaging transducer. The transducer ablates a volume of $0.9 \times 0.2 \times 0.2 \mathrm{~cm}$. A visualisation and treatment unit is connected to the Echopulse and is used for target tissue imaging, power delivery, temperature measurements of the cooling liquid and pressure within the membrane covering the transducer. The skin is cooled during the treatment and cooling liquid is regulated at the membrane and flows from the device towards the probe. Thus far, the Echopulse device has only been used for the treatment of benign breast lesions and not breast cancer.

The second US-guided HIFU device is the Model-JC HIFU system (Haifu Technology, Chongqing, China). This device is CE-marked for the application in solid tumours in soft tissues, including uterine fibroids and adenomyosis, liver tumours, kidney tumours, breast tumours, bone tumours and pancreas tumours. This device uses a $3.5 \mathrm{MHz}$ diagnostic transducer and a $1.6 \mathrm{MHz}$ therapeutic imaging transducer $[7,19,21]$. In breast disease, this device has only been used in the treatment of breast cancer.

Guidance with MRI has the advantage of excellent anatomical resolution, high sensitivity for the detection of lesions and temperature mapping. The high sensitivity of MRI-guided HIFU allows for very precise treatment planning and an accurate evaluation of the efficacy of the treatment at the end of the procedure [20]. However, temperature mapping is complicated due to the high amount of fat and lack of reliability of water proton phase shift-based measurements within fat [22]. Other disadvantages are the high cost, the need for a radiologist and the reduced mobility of the device.

MRI-guided HIFU has been CE-marked for use in uterine fibroids, neurological lesions, adenomyosis and pain palliation of bone metastases; however, the application in breast is still awaiting CE and FDA marking. Currently, the most commonly used devices are the ExAblate 2000 and 2100 systems designed by InSightec-TxSonics Ltd (Haifa, Israel and Dallas, TX) and the Sonalleve MR HIFU system (Philips, Best, The Netherlands). The ExAblate device has been integrated into a 1.5 T MRI scanner (GE Medical systems, Milwaukee, WI) [23]. The device consists of four elements; the MRI unit, the HIFU table, the control personal computer and the HIFU workstation and console. The HIFU table consists of a normal MRI table which is modified to contain a US transducer which is mounted on a mechanical arm and immersed into a water bath. The HIFU workstation consists of a personal computer which communicates with the MRI console computer and the control personal computer and therefore the operator controls the integrated MRI-guided HIFU procedure from the HIFU workstation [24].

A more recently developed system is the Sonalleve MR HIFU system (Philips, The Netherlands), which combines MRI and HIFU in order to be able to perform ablations up to $1.6 \times 4.0 \mathrm{~cm}$ in volume. It provides temperature-sensitive images in order to determine the location of critical structures and monitor the heat produced. Temperature mapping information is used straight away in order to adjust the treatment; this feedback can help in correcting for local variations in the tissue which can result in inhomogeneous absorption, attenuation and, therefore, overheating. It uses a double membrane with cooled water in order to cool the skin during treatment and measures cumulative heating during the whole treatment. This information is looped back in order to determine the ideal cooling times between pulses reducing the complication rate. Prior to treatment, the patient is placed prone on the treatment table and the target breast is placed into the centre of a ring-shaped MRI surface coil [24]. Pre-treatment MRIs are acquired followed by HIFU treatment. After every sonication the target volume is verified using a temperature-sensitive phase map MRI. After completion of the treatment, another set of MRIs are performed [23].

\section{US-guided HIFU studies}

The first US-guided HIFU studies were performed using patients with breast cancer; however, more recently US-guided HIFU has been used in three trials with breast FAD (Table 1a). 
A review by Cavallo Marincola et al [20] presented the result of using this device in ten patients with breast FAD. At three months' follow-up, a $50 \%$ reduction in the maximum diameter was seen on US. No adverse events were reported. Kovatcheva et al [25] recently reported a study including 42 patients with 51 FAD. A reduction of $59.2 \pm 18.2 \%$ was seen on US after six months and $72.5 \pm 16.7 \%$ after one year of follow-up. Skin burns were reported in three patients and hyperpigmentation in one patient. Peek et al [26] performed an initial study on 20 patients and 20 control patients with breast FAD. Circumferential HIFU treatment was performed by delivering two treatment rings at the circumference of the lesion and deselecting the centre of the FAD. Circumferential ablation was found to achieve a reduction in treatment time of $37.5 \pm 20.1 \%$ compared to whole lesion ablation. On US, a significant reduction in FAD volume of $43.5 \pm 38.8 \%(p=0.016)$ after six months was observed in the HIFU group and a non-significant reduction of $4.6 \pm 46.0 \%(p=0.530)$ in the control group, making the reduction between the two groups significantly different $(p=0.002)$. In addition, pre-treatment pain resolved after six months in six of eight patients $(75 \%)$.

Four studies of breast cancer were included in the systematic review by Peek et al [27], who were evaluating all HIFU studies performed in breast tumours. The first study, by Wu et al [19], included 23 patients treated with HIFU followed by resection of the tumours one to two weeks post-treatment. Staining with haematoxylin and eosin (H\&E) showed complete ablation in all patients. A skin burn was the only adverse event reported in one patient. In a second study by Wu et al [21], 22 patients were treated with HIFU and followed up for a median period of 54.8 months (range 36-72 months). Core needle biopsies taken at two weeks, three, six and 12 months showed no viable tumour cells in all patients. No adverse events were observed post-treatment, but two patients developed local recurrence after 18 and 22 months post-treatment.

Kim et al [7] included six patients with breast cancer. Patients were followed up by dynamic MRI two weeks post-treatment; if no enhancement was visible, patients were followed up with MRI. If nodular or irregular thick enhancement was visible at the ablated tumour periphery, a US-guided biopsy and a second HIFU session were recommended. Complete ablation was seen in $66.7 \%$ of patients. Reported adverse events were injury to the pectoralis major $(n=6)$, nipple depression $(n=1)$ and skin defect $(n=1)$. The last study was performed by Guan et al [28], who performed a randomised controlled trial and included 25 patients who were treated with the JC HAIFU device. This study showed that HIFU caused coagulative ablation of the tumour and a margin of $1.9 \pm 0.4 \mathrm{~cm}$ of normal tissue. No complications other than fever in three patients were found.

\section{MRI-guided HIFU studies}

MRI-guided HIFU has only been used once in the treatment of benign breast FAD (Table 1b), by Hynynen et al [12] in a small study of nine patients and eleven FAD. Complete ablation was seen in $54 \%$ of patients. Pectoralis major injury was reported in one patient.

Ten studies performed MRI-guided HIFU in the treatment of breast cancer. These studies were included in the systematic review by Peek et al [27] evaluating all HIFU studies performed in breast tumours.

Huber et al [29] performed a case study of a 56-year-old patient with a $2.2 \mathrm{~cm}$ tumour. Resection took place five days post-treatment and showed complete ablation of the tumour. Gianfelice et al $[23,24,30]$ performed three studies with 12,17 and 24 patients, respectively. In the first study [24], resection was performed immediately post-treatment and showed complete ablation in $17 \%$ of patients. Two patients developed a skin burn during treatment. In the second study [23], resection was performed 3-21 days post-treatment and histopathological staining with H\&E showed complete ablation in $24 \%$ of patients. No adverse events occurred. In the third study [30], patients were followed up for an average of 20.2 months (range 12-39 months). After six months, core needle biopsies were performed, which showed no viable tumour in $58.3 \%$ of patients. Ten patients underwent a second HIFU treatment after which another five patients were disease free. In total, complete ablation was obtained in $79 \%$ of all patients and one patient developed a skin burn during HIFU treatment.

Zippel et al [31] performed HIFU in ten patients and excised the tumour seven to ten days post-treatment. Complete ablation was seen on histopathology (staining unknown) in $20 \%$ of patients and two patients developed skin burns during treatment. Khiat et al [32] performed another study with 25 patients. Tumours were resected within 3-21 days and complete ablation was visible in $30 \%$ of patients. No adverse events were reported. 
Table 1. (a) US-guided trials.

\begin{tabular}{|c|c|c|c|c|c|c|c|c|c|}
\hline Study & $\mathbf{n}$ & FAD /BC & Size $(\mathrm{cm})^{*}$ & $\begin{array}{c}\text { Age } \\
\text { (years) }^{*}\end{array}$ & Device & CA & Resection & Complications & $\begin{array}{l}\text { Time } \\
(\min )^{\star}\end{array}$ \\
\hline Wu (2003) & 23 & $\mathrm{BC}$ & $\begin{array}{l}3.1 \pm 0.8 \\
(2.0-4.7)\end{array}$ & $46.5 \pm 1.7$ & JC HAIFU & $100 \%$ (H\&E) & $1-2 \mathrm{wk}$ & Skin burn (1) & $\begin{array}{c}78 \\
(45-150)^{1}\end{array}$ \\
\hline Wu (2005) & 22 & $\mathrm{BC}$ & $\begin{array}{l}3.4 \\
(2.0-4.8)\end{array}$ & $\begin{array}{l}48.6 \\
(36-68)\end{array}$ & JC HAIFU & $100 \%$ (H\&E) & $\begin{array}{l}\text { Follow-up } \\
54.8 \mathrm{M}(36-72)^{1}\end{array}$ & Recurrence (2) & $\begin{array}{c}132 \\
(60-180)^{1}\end{array}$ \\
\hline Kim (2010) & 6 & $\mathrm{BC}$ & $\begin{array}{l}2.56 \\
(1.2-3.7)\end{array}$ & $\begin{array}{l}62.1 \\
(46-68)\end{array}$ & JC HAIFU & $67 \%$ & $\begin{array}{l}\text { Delayed excision } \\
\text { and follow-up } \\
\text { 2-30 M }\end{array}$ & $\begin{array}{l}\text { Pectoralis major } \\
\text { injury (6), nipple } \\
\text { depression (1), } \\
\text { skin defect (1) }\end{array}$ & $\begin{array}{c}174.4 \\
(80-285)\end{array}$ \\
\hline $\begin{array}{l}\text { Cavallo- } \\
\text { Marincola } \\
(2010)\end{array}$ & 10 & FAD & - & $\begin{array}{l}26 \\
(18-34)^{1}\end{array}$ & JC HAIFU & $\begin{array}{l}50 \% \text { reduction } \\
\text { after in maximum } \\
\text { diameter after three } \\
\text { months }\end{array}$ & - & $\begin{array}{l}\text { Swelling, } \\
\text { hardness of area }\end{array}$ & $\begin{array}{c}57.2 \\
(40-100)^{1}\end{array}$ \\
\hline $\begin{array}{l}\text { Kovatcheva } \\
(2015)\end{array}$ & $\begin{array}{l}42 \\
(51)\end{array}$ & FAD & $\begin{array}{l}3.9 \mathrm{ml} \\
(0.3-19.7)^{1}\end{array}$ & $\begin{array}{l}32 \\
(16-52)^{1}\end{array}$ & Echopulse & $\begin{array}{l}\text { Reduction of } 33.2 \\
\pm 19.1 \% \text { at two } \\
\text { months, } 59.2 \pm \\
18.2 \% \text { at six months } \\
\text { and } 72.5 \pm 16.7 \% \text { at } \\
12 \text { months }\end{array}$ & Follow-up $12 \mathrm{M}$ & $\begin{array}{l}\text { Skin burn ( } 3 \text { ), } \\
\text { hyper-pigmenta- } \\
\text { tion (1) }\end{array}$ & $\begin{array}{c}118 \\
(60-255)^{1}\end{array}$ \\
\hline $\begin{array}{l}\text { Guan } \\
\text { (2016) }\end{array}$ & 25 & $\mathrm{BC}$ & $(2.1-4.8)$ & $\begin{array}{l}48 \\
(22-63)\end{array}$ & JC HAIFU & - & $1-2 \mathrm{wk}$ & Fever (3) & $\begin{array}{c}66 \\
(40-132)^{1}\end{array}$ \\
\hline Peek (2016) & 20 & FAD & $7.3 \pm 10.1 \mathrm{~cm}^{3}$ & $\begin{array}{l}30.3 \pm 7.5 \\
(18-45)\end{array}$ & Echopulse & $\begin{array}{l}\text { Reduction of } 16.8 \\
\pm 19.3 \% \text { after two } \\
\text { weeks, } 30.9 \pm \\
52.7 \% \text { after three } \\
\text { months and } 43.5 \\
\pm 38.8 \% \text { after six } \\
\text { months }\end{array}$ & Follow-up $6 \mathrm{M}$ & $\begin{array}{l}\text { Ecchymosis (9), } \\
\text { erythema (6), } \\
\text { hypo-pigmenta- } \\
\text { tion (1), dimpling } \\
\text { (1), numbness } \\
\text { (1), skin burn (1), } \\
\text { hyper-pigmenta- } \\
\text { tion (6) }\end{array}$ & 34.6 \\
\hline
\end{tabular}

Table 1. (b) MRI-guided trials.

\begin{tabular}{|c|c|c|c|c|c|c|c|c|c|}
\hline Study & $\mathbf{n}$ & FAD /BC & Size $(\mathrm{cm})^{*}$ & $\begin{array}{c}\text { Age } \\
\text { (years) }^{*}\end{array}$ & Device & CA & Resection & Complications & $\begin{array}{l}\text { Time } \\
(\min )^{*}\end{array}$ \\
\hline Huber (2001) & 1 & $\mathrm{BC}$ & $2.2 \times 2.0 \times 1.4$ & 56 & Unknown & $100 \%$ & $5 \mathrm{D}$ & - & 90 \\
\hline Gianfelice (2003) & 12 & $\mathrm{BC}$ & $\begin{array}{l}2.8 \mathrm{~cm}^{3} \\
(0.1-8.8)\end{array}$ & $\begin{array}{l}60 \pm 9.6 \\
(45-74)\end{array}$ & ExAblate 2000 & $17 \%(\mathrm{H} \& \mathrm{E})$ & $\begin{array}{l}\text { Delayed } \\
\text { (unknown time) }\end{array}$ & Skin burn (2) & $\begin{array}{l}80 \\
(35-133)\end{array}$ \\
\hline Gianfelice (2003) & 17 & $\mathrm{BC}$ & $\begin{array}{l}1.5 \mathrm{~cm}^{3} \\
(0.1-8.8)\end{array}$ & $\begin{array}{l}61.2 \pm 8.9 \\
(48-76)\end{array}$ & ExAblate 2000 & $24 \%(H \& E)$ & 3-21 D & - & - \\
\hline Gianfelice (2003) & 24 & $\mathrm{BC}$ & $\begin{array}{l}1.5 \\
(0.6-2.5)\end{array}$ & $\begin{array}{l}74.2 \\
(53-92)\end{array}$ & ExAblate 2000 & $79 \%$ & $\begin{array}{l}\text { Follow-up } \\
20.2 \mathrm{M}(12-39)\end{array}$ & Skin burn (1) & - \\
\hline Zippel (2005) & 10 & $\mathrm{BC}$ & 2.2 & $\begin{array}{l}56 \\
(45-72)\end{array}$ & ExAblate 2000 & $20 \%$ & $7-10 \mathrm{D}$ & Skin burn (1) & Max 240 \\
\hline Khiat (2006) & $\begin{array}{c}25 \\
(26)\end{array}$ & $\mathrm{BC}$ & $\begin{array}{l}3.3 \mathrm{~cm}^{3} \\
(0.1-11.2)\end{array}$ & $\begin{array}{l}61.3 \pm 11 \\
(45-87)\end{array}$ & ExAblate 2000 & $31 \%$ & 3-21 D & - & - \\
\hline
\end{tabular}


Table 1. (b) Continued.

\begin{tabular}{|c|c|c|c|c|c|c|c|c|c|}
\hline Furusawa (2006) & 28 & $\mathrm{BC}$ & $\begin{array}{l}1.3 \\
(0.5-2.5)\end{array}$ & $\begin{array}{l}56.9 \\
(41-79)\end{array}$ & ExAblate 2000 & $\begin{array}{l}53.5 \% \\
\text { (H\&E) }\end{array}$ & $5-23 \mathrm{D}$ & Skin burn (1) & $\begin{array}{l}140 \\
(76-231)\end{array}$ \\
\hline Furusawa (2007) & 21 & $\mathrm{BC}$ & $\begin{array}{l}1.5 \\
(0.5-5.0)^{1}\end{array}$ & $\begin{array}{l}54 \\
(34-72)^{1}\end{array}$ & ExAblate 2000 & - & $\begin{array}{l}\text { Follow-up } \\
14 \mathrm{M}(3-26)^{1}\end{array}$ & $\begin{array}{l}\text { Skin burn (2), } \\
\text { recurrence (1) }\end{array}$ & - \\
\hline $\begin{array}{l}\text { Cavallo- } \\
\text { Marincola (2013) }\end{array}$ & 10 & $\mathrm{BC}$ & 1.2 & - & ExAblate 2000 & $60 \%$ & $24-35 \mathrm{D}$ & - & $\begin{array}{l}140 \\
(80-180)\end{array}$ \\
\hline Merckel (2015) & 10 & $\mathrm{BC}$ & $2.0 \pm 0.6$ & $54.8 \pm 12.5$ & Sonalleve & - & $5.0 \pm 2.2 \mathrm{D}$ & White lumps (1) & $\begin{array}{l}46 \pm 17 \\
(12-75)\end{array}$ \\
\hline
\end{tabular}

*Values are mean \pm SD (range), unless indicated otherwise by ${ }^{1}, F A D$ - fibroadenomata, BC - breast cancer, $d$ - days, wk - weeks, $m$ - months

Furusawa et al [33, 34] performed two studies with 28 and 21 patients. In the first study with 28 patients, tumours were excised five to 23 days post-treatment. Complete ablation was seen in $53.5 \%$ of patients and one patient developed a skin burn during treatment. In the second study [34], 21 patients were treated and followed up for a median of 14 months (range 3-26 months). Skin burns were observed in two patients and recurrence was seen in one patient.

Most recently, Cavallo Marincola et al [20] performed a non-randomised treat and resect study on ten patients with biopsy-proven singlefocus invasive ductal carcinoma. Post-HIFU MRI was performed 10-21 days after HIFU treatment and 14 days after MRI resection of the tumour was planned. The average tumour size was $1.2 \mathrm{~cm}$ and the average treatment time was 140 minutes (range $80-180$ minutes). No adverse events were reported. In $60 \%$ of patients, no enhancement was seen on MRI and this was confirmed on histopathology. In $20 \%$ of patients, MRI showed residual enhancing tissue and this was confirmed on histopathology. In $20 \%$ of patients, no enhancement was seen on MRI but histopathology showed a small focus of viable cells in the centre of the ablative area. After six months' follow-up, no evidence of recurrence was seen in any patients on imaging. In addition, Merckel et al [35] performed a study in ten patients with early stage breast cancer. Tissue necrosis was observed in six out of ten patients and no complications were found apart from white lumps in one patient. The mean treatment time was $46 \pm 17$ minutes (12-75 minutes).

\section{Challenges of HIFU}

Although these trials have shown great potential for the use of HIFU in the treatment of both FAD and breast cancer, there are a few challenges which require to be solved before HIFU can be used more widely. Although studies demonstrated high percentages of complete radiological ablation, complete pathological ablation is not consistently obtained in all patients and therefore this technique should be further developed in order to achieve this. The lack of complete histopathological ablation in all patients can be affected by multiple factors. Immobilisation is very important in order to make sure that the treatment is delivered at the correct location, movements due to breathing or pain felt by the patient or due to discomfort caused by the treatment bed are common and should be avoided or reduced to a minimum during treatment. General anaesthesia is not ideal as this brings along additional complications, requires an anaesthetist and prolongs the hospital stay of the patient. However, local anaesthesia was found to be unable to remove all pain caused by the treatment, resulting in movement of the patient [26]. Conscious sedation, a pectoralis major block or a combination of local anaesthesia techniques might be more effective in order to reduce the pain and make the patients more comfortable and relaxed during the treatment. In addition, a well-designed immobilisation covering the complete breast is recommended in order to reduce movements caused by breathing or the heart. Real-time imaging is very important in order to visualise the tumour, follow the progress of the treatment and be able to amend the treatment where necessary. If the quality of the imaging is not high enough the lesion will disappear from the screen and pathological complete ablation will be difficult to obtain as the treatment cannot be followed or corrected when necessary. These difficulties need to be solved before HIFU can be widely used in practice.

Several other ablative techniques are available, such as radiofrequency ablation, laser ablation and microwave ablation, all of which use heat and cryo-ablation which uses freezing to ablate benign and malignant breast tumours. Compared to these techniques, HIFU is the only non-invasive technique as all other techniques require the insertion of needles or probes, which carries additional risks such as skin 
burns and scarring. Two systematic reviews and meta-analyses were performed, evaluating minimally invasive techniques. [6, 36] These found that HIFU had the highest percentage of technical success, but that in terms of technique efficacy or percentage of complete ablation, techniques as radiofrequency ablation, cryo-ablation and laser ablation are better.

Compared to breast conserving surgery, HIFU does not need general anaesthesia or tissue loss, therefore potentially reducing the risk of procedure-related complications and improving cosmetic outcome.

\section{Conclusions}

Over the years, HIFU has been developed as a non-invasive ablative technique in the treatment of both benign and malignant breast tumours. Tumours can be treated under US or MRI guidance and both modalities show promising results. HIFU should also be further developed in large prospectively conducted clinical trials to validate the efficacy of HIFU compared to surgery.

\section{Conflicts of interest}

The authors declare that they have no conflicts of interest.

\section{Acknowledgments}

We would like to thank Theraclion Ltd (Malakoff, France) for an educational grant to fund our research work.

\section{References}

1. Breast Cancer (2014) pp 1-2

2. Fornage BD and Hwang RF (2014) Current status of imaging-guided percutaneous ablation of breast cancer AJR Am J Roentgenol 203(2) 442-448 https://doi.org/10.2214/AJR.13.11600 PMID: 25055283

3. Roubidoux MA, Yang W, and Stafford RJ (2014) Image-guided ablation in breast cancer treatment Tech Vasc Interv Radiol 17(1) 49-54 https://doi.org/10.1053/j.tvir.2013.12.008 PMID: 24636331

4. Greenberg R, Skornick Y, and Kaplan O (1998) Management of breast fibroadenomas J Gen Intern Med 13(9) 640-645 https://doi. org/10.1046/j.1525-1497.1998.cr188.x PMID: $\underline{9754521}$ PMCID: 1497021

5. Fisher B, Anderson S, and Bryant J, et al (2002) Twenty-year follow-up of a randomized trial comparing total mastectomy, lumpectomy, and lumpectomy plus irradiation for the treatment of invasive breast cancer N Engl J Med 347(16) 1233-1241 https://doi.org/10.1056/NEJMoa022152 PMID: 12393820

6. Peek MC, Ahmed M, and Napoli A, et al (2016) Minimal invasive ablative techniques in the treatment of breast cancer: a systematic review Int $J$ Hyperthermia 2 1-12

7. Kim SH, Jung SE, and Kim HL, et al (2010) The potential role of dynamic MRI in assessing the effectiveness of high-intensity focused ultrasound ablation of breast cancer Int J Hyperthermia 26(6) 594-603 https://doi.org/10.3109/02656736.2010.481275 PMID: 20707653

8. Schmitz AC, Gianfelice D, and Daniel BL, et al (2008) Image-guided focused ultrasound ablation of breast cancer: current status, challenges, and future directions Eur Radiol 18(7) 1431-1441 https://doi.org/10.1007/s00330-008-0906-0 PMID: 18351348 PMCID: 2441491 
9. Bradley Jr WG (2009) MR-guided focused ultrasound: a potentially disruptive technology J Am Coll Radio/ 6(7) 510-513 https:// doi.org/10.1016/j.jacr.2009.01.004

10. Fry WJ and Fry FJ (1960) Fundamental neurological research and human neurosurgery using intense ultrasound IRE Trans Med Electron Me-7 166-181 https://doi.org/10.1109/IRET-ME.1960.5008041 PMID: 13702332

11. Oka M (1958) Clinical use of ultrasonics and related biological research in Japan Am J Phys Med 37(4) 210-218 PMID: 13559415

12. Hynynen K and Lulu BA (1990) Hyperthermia in cancer treatment Invest Radiol 25(7) 824-834 https://doi.org/10.1097/00004424199007000-00014 PMID: 2202694

13. Dubinsky TJ, Cuevas C, and Dighe MK, et al (2008) High-intensity focused ultrasound: current potential and oncologic applications Am J Roentgenol 190(1) 191-199 https://doi.org/10.2214/AJR.07.2671

14. Haar GT and Coussios C (2007) High intensity focused ultrasound: physical principles and devices Int J Hyperthermia 23(2) 89-104 https://doi.org/10.1080/02656730601186138 PMID: 17578335

15. White PJ, Clement GT, and Hynynen K (2006) Local frequency dependence in transcranial ultrasound transmission Phys Med Biol 51(9) 2293-2305 https://doi.org/10.1088/0031-9155/51/9/013 PMID: 16625043 PMCID: 1560343

16. Thanou M and Gedroyc W (2013) MRI-guided focused ultrasound as a new method of drug delivery J Drug Deliv 2013616197 https://doi.org/10.1155/2013/616197 PMID: 23738076 PMCID: $\underline{3666208}$

17. Hill CR (1994) Optimum acoustic frequency for focused ultrasound surgery Ultrasound Med Biol 20(3) 271-277 https://doi. org/10.1016/0301-5629(94)90067-1 PMID: $\underline{8059488}$

18. Zderic V, Keshavarzi A, and Andrew MA, et al (2004) Attenuation of porcine tissues in vivo after high-intensity ultrasound treatment Ultrasound Med Biol 30(1) 61-66 https://doi.org/10.1016/j.ultrasmedbio.2003.09.003 PMID: 14962609

19. Wu F, Wang ZB, and Cao YD, et al (2003) A randomised clinical trial of high-intensity focused ultrasound ablation for the treatment of patients with localised breast cancer Br J Cancer 89(12) 2227-2233 https://doi.org/10.1038/sj.bjc.6601411 PMID: 14676799 PMCID: 2395272

20. Cavallo Marincola B, Pediconi F, and Anzidei M, et al (2015) High-intensity focused ultrasound in breast pathology: non-invasive treatment of benign and malignant lesions Expert Rev Med Devices 12(2) 191-199 https://doi.org/10.1586/17434440.2015.986096

21. Wu F, Wang ZB, and Zhu H, et al (2005) Extracorporeal high intensity focused ultrasound treatment for patients with breast cancer Breast Cancer Res Treat 92(1) 51-60 https://doi.org/10.1007/s10549-004-5778-7 PMID: 15980991

22. Kuroda K, Oshio K, and Mulkern RV (1998) Optimization of chemical shift selective suppression of fat Magn Reson Med 40(4) 505-510 https://doi.org/10.1002/mrm.1910400402 PMID: 9771566

23. Gianfelice D, Khiat A, and Amara M, et al (2003) MR imaging-guided focused ultrasound surgery of breast cancer: correlation of dynamic contrast-enhanced MRI with histopathologic findings Breast Cancer Res Treat 82(2) 93-101 https://doi.org/10.1023/ B:BREA.0000003956.11376.5b PMID: 14692653

24. Gianfelice D, Khiat A, and Amara M, et al (2003) MR imaging-guided focused US ablation of breast cancer: histopathologic assessment of effectiveness - initial experience Radiology 227(3) 849-855 https://doi.org/10.1148/radiol.2281012163 PMID: 12714680

25. Kovatcheva R, Guglielmina JN, and Abehsera M, et al (2015) Ultrasound-guided high-intensity focused ultrasound treatment of breast fibroadenoma-a multicenter experience $J$ Ther Ultrasound 3(1) 1 https://doi.org/10.1186/s40349-014-0022-3 PMID: 25635224 PMCID: $\underline{4310188}$

26. Peek MC, Ahmed M, and Scudder J, et al (2016) High intensity focused ultrasound in the treatment of breast fibroadenomata: results of the HIFU-F trial Int J Hyperthermia 32(8) 881-888 https://doi.org/10.1080/02656736.2016.1212278 PMID: 27484113 
27. Peek MCL, Ahmed M, and Napoli A, et al (2015) Systematic review of high-intensity focused ultrasound ablation in the treatment of breast cancer Br J Surg 102(8) 873-882 https://doi.org/10.1002/bjs.9793

28. Guan L and Xu G (2016) Damage effect of high-intensity focused ultrasound on breast cancer tissues and their vascularities World J Surg Oncol 14(1) 153 https://doi.org/10.1186/s12957-016-0908-3 PMID: 27230124 PMCID: 4882851

29. Huber PE, Jenne JW, and Rastert R, et al (2001) A new noninvasive approach in breast cancer therapy using magnetic resonance imaging-guided focused ultrasound surgery Cancer Res 61(23) 8441-8447 PMID: 11731425

30. Gianfelice D, Khiat A, and Boulanger $Y$, et al (2003) Feasibility of magnetic resonance imaging-guided focused ultrasound surgery as an adjunct to tamoxifen therapy in high-risk surgical patients with breast carcinoma $J$ Vasc Interv Radiol 14(10) 1275-1282 https://doi.org/10.1097/01.RVI.0000092900.73329.A2 PMID: 14551274

31. Zippel DB and Papa MZ (2005) The use of MR imaging guided focused ultrasound in breast cancer patients; a preliminary phase one study and review Breast Cancer 12(1) 32-38 https://doi.org/10.2325/jbcs.12.32 PMID: 15657521

32. Khiat A, Gianfelice D, and Amara M, et al (2006) Influence of post-treatment delay on the evaluation of the response to focused ultrasound surgery of breast cancer by dynamic contrast enhanced MRI Br J Radiol 79(940) 308-314 https://doi.org/10.1259/ bir/23046051 PMID: 16585723

33. Furusawa $\mathrm{H}$, Namba $\mathrm{K}$, and Thomsen $\mathrm{S}$, et al (2006) Magnetic resonance-guided focused ultrasound surgery of breast cancer: reliability and effectiveness J Am Coll Surg 203(1) 54-63 https://doi.org/10.1016/j.jamcollsurg.2006.04.002 PMID: 16798487

34. Furusawa $\mathrm{H}$, Namba $\mathrm{K}$, and Nakahara $\mathrm{H}$, et al (2007) The evolving non-surgical ablation of breast cancer: MR guided focused ultrasound (MRgFUS) Breast Cancer 14(1) 55-58 https://doi.org/10.2325/jbcs.14.55 PMID: 17244995

35. Merckel LG, Knuttel FM, and Deckers R, et al (2016) First clinical experience with a dedicated MRI-guided high-intensity focused ultrasound system for breast cancer ablation Eur Radiol 26(11) 4037-4046 https://doi.org/10.1007/s00330-016-4222-9 PMID: 26852219 PMCID: $\underline{5052313}$

36. Mauri G, Sconfienza LM, and Pescatori LC, et al (2017) Technical success, technique efficacy and complications of minimallyinvasive imaging-guided percutaneous ablation procedures of breast cancer: a systematic review and meta-analysis Eur Radio/ 27(8) 3199-3210 https://doi.org/10.1007/s00330-016-4668-9 PMID: 28050693 